\title{
LA COMISION ASESORA DE LIBERTAD RELIGIOSA
}

POR

JOSE ANTONIO SOUTO PAZ

Catedrático de la Universidad de Santiago de Compostela

\section{SUMARIO}

I. Introducción: 1. Una Comisión para la libertad religiosa.-II. PresuPUESTOS CONSTITUCIONALES: 1 . La «cuestión religiosa» y la solución constitucional. 2. La libertad religiosa como principio constitucional de regulación del factor religioso. 3. El reconocimiento constitucional de las confesiones religiosas. 4. La igualdad constitucional de las confesiones. 5. La mención explicita de la Iglesia católica. 6. Las relaciones de cooperación del Estado con las confesiones.-III. Desarrollo legislativo: 1. La Ley Orgánica de Libertad Religiosa. 2. La creación de la Comisión Asesora de Libertad Religiosa. 3. Composición. 4. Competencia: a) por razón de la materia; b) por razón de los sujetos; c) por razón del procedimiento. 5. Funcionamiento.

\section{INTRODUCCION}

\section{Una Comisión para la libertad religiosa}

La Ley Orgánica de Libertad Religiosa ${ }^{1}$ dispone la creación en el Ministerio de Justicia de una Comisión que ejerza una función consultiva en todas aquellas cuestiones relacionadas con la aplicación de dicha Ley ${ }^{2}$. La Comisión Asesora de Libertad Religiosa se instituye con el ánimo de interpretar y aplicar con las mayores garantías posibles el principio de libertad religiosa, consagrado en nuestra Constitución y desarrollado por la LOLR. Con esta finalidad se establece que la Comisión tenga una composición plural en la que estén representadas —además de la Administración - las confesiones religiosas y avalada

${ }^{1}$. Ley Orgánica 7/1980, de 5 de julio de 1980, de Libertad Religiosa (BOE de 24-7-1980). En lo sucesivo la citaremos con la abreviatura LÓLR.

${ }^{2}$ LOLR, art. 8. 
su actuación con la presencia de expertos, cuya reconocida competencia garantice el mejor cumplimiento de los objetivos asignados a la Comisión ${ }^{3}$.

El cambio sustancial que supone el paso de un régimen confesional -vigente en el régimen anterior y tradicional en España- a un régimen de libertad religiosa ${ }^{4}$, que en los términos actuales constituye una verdadera innovación en nuestro país, es evidente que planteará problemas difíciles de adaptación a la nueva situación. Ello hace especialmente importante la función de la Comisión Asesora, que, por su composición plural, podrá desbrozar en su primera fase, a través de sus informes y dictámenes, los problemas que el nuevo sistema eclesiástico español va a reportar.

Para una mejor comprensión de la relevancia y de la competencia de esta nueva Comisión parece obligado interpretar el sentido y el contenido del derecho de libertad religiosa en la Constitución y analizar posteriormente las cuestiones jurídicas que el desarrollo legislativo posterior puede plantear. Al análisis de estas cuestiones dedicamos las páginas que siguen.

\section{PRESUPUESTOS CONSTITUCIONALES}

\section{La «cuestión religiosa» y la solución constitucional}

La civilización occidental hubo de recorrer un largo camino hasta encontrar una solución racional al problema religioso. Entre la concepción teoctática o hierocrática, dominante en la Edad Media, y la declaración de la libertad religiosa como un derecho fundamental de los ciudadanos tiene lugar un largo proceso de evolución ideológica, en medio de fuertes tensiones políticas y sociales que en ocasiones llegaron a adquirir el nivel de «guertas de religión» ${ }^{5}$.

Los Estados modernos, que nacen de la quiebra del mundo cristiano medie-

${ }^{3}$ El art. 8 de la LOLR ha sido desarrollado por el Real Decreto 1980/1981, de 19 de junio, sobre constitución de la Comisión Asesora de Libertad Religiosa en el Ministerio de Justicia. El art. 1 regula la composición de la Comisión.

${ }_{4}$ Véase A. Fuenmayor, «Problemas actuales de la confesionalidad del Estado», en Ius Canonicum (1966), págs. 375-402; íd., «Estado y religión: el art. $60^{\circ}$ del Fuero de los Españoles», en Revista de Estudios Políticos, 1967, págs. 99-120; P. Lombardía, «La confesionalidad del Estado hoy», en Ius Canonicum, núm. 1, 1961, págs. 329-350; I. Martín, «Estado y religión en la vigente Constitución española», en Lex Ecclesiae. Estudios en bonor del profesor M. Cabreros de Anta, Salamanca, 1972, págs. 563-578; A. de la Hera, Pluralismo y libertad religiosa, Sevilla, 1971; íd., «Confesionalidad del Estado y libertad religiosa», en Ius Canonicum, núm. 12, 1972, págs. 87-104; C. Presas, De la confesionalidad del Estado al régimen de libertad religiosa en España, Santiago, 1981; J. Rupérez, Estado confesional y libertad religiosa, Madrid, 1970; G. Suárez Pertierra, Libertad religiosa y confesionalidad en el ordenamiento jurídico español, Vitoria, 1978.

5 Véase Ehler, Historia de las relaciones entre la Iglesia y el Estado, Madrid, 1966; A. de la Hera, «Evolución de las doctrinas sobre las relaciones entre la Iglesia y el poder temporal», en Derecbo Canónico, v. II, Pamplona, 1974, págs. 241-282; E. Gallego Blanco, Relaciones entre la Iglesia y el Estado en la Edad Media, Madrid, 1973; P. Lombardía, «Síntesis histórica», en Derecho eclesiástico del Estado español, Pamplona, 1980, págs. 39150; V. Reina, «Los términos de la polémica sacerdocio-reino», en Ius Canonicum, núm. 6, 1966, págs. 153-199. 
val, hacen suya una religión y la imponen a sus súbditos. El Estado confesional practica la intolerancia persiguiendo a los súbditos que no profesan la religión del Estado o modera su intransigencia tolerando la práctica privada de cultos diferentes a la confesión estatal. El ciudadano, en cualquier caso, no tiene derecho a profesar y practicar libremente sus creencias religiosas. El reconocimiento de este derecho es un logro tardío que se va recogiendo paulatinamente en las legislaciones contemporáneas ${ }^{6}$.

En España el proceso es más lento. Las Constituciones del siglo XIx mantienen la confesionalidad del Estado y el laicismo de la Constitución de la II República es tan sólo un caso aislado agravado por un erróneo planteamiento del principio y de su aplicación práctica. Por supuesto, no resuelve la «cuestión religiosa», planteada anteriormente como discriminación de los no católicos. Por el contrario, agudiza el problema como consecuencia de un laicismo beligerante y anacrónico en relación con los católicos ?.

La Constitución de 1978 ha establecido un sistema de equilibrio, respetuoso con los sentimientos religiosos y neutral en relación con cada confesión, al proclamar que ninguna tendrá carácter estatal. En efecto, el texto constitucional garantiza la protección de la libertad religiosa con una fórmula original, inspirada en la libertad y la concordia, con la que se pretende resolver la «cuestión religiosa» que durante años ha dividido a los españoles. La solución constitucional constituye, en efecto, una novedad en relación con las fórmulas adoptadas en las precedentes Constituciones españolas. Basta un breve repaso de las mismas para observar que el artículo 16 de nuestra Constitución resulta tan lejano de las declaraciones de confesionalidad de las Constituciones del siglo XIX como del separatismo laicista de la Constitución republicana de $1931^{8}$.

El artículo 16 garantiza «la libertad... religiosa y de culto de los individuos y comunidades» y declara que «nadie podrá ser obligado a declarar sobre su... religión o creencias». Añade que «ninguna religión tendrá carácter estatal», si bien «los poderes públicos tendrán en cuenta las creencias religiosas de la sociedad española y mantendrán las consiguientes relaciones de cooperación con la Iglesia católica y las demás confesiones».

Aun siendo el artículo 16 el texto específico en el que se reconoce la libertad religiosa y se regulan sus rasgos más característicos, no se puede olvidar

- Véanse P. Fedele, La libertà religiosa, Milán, 1963; L. de Luca, Diritto ecclesiastico ed esperienza giuridica, Milán, 1970; S. Lariccia, Diritti civili e fattore religioso, Bolonia, 1978; C. Corral, La libertad religiosa en la Comunidad Europea, Madrid, 1973.

7 Véanse F. de Meer, La cuestión religiosa en las Cortes Constituyentes de la II República española, Pamplona, 1975; J. M. Cuenca, La Iglesia española ante la revolución liberal, Madrid, 1971; V. Cárcel, Política eclesial de los Gobiernos liberales españoles, 1830-1840, Pamplona, 1975.

${ }^{8}$ Véanse Varios, «El hecho religioso en la nueva Constitución española», en XVI Semana de Derecho Canónico, Salamanca, 1979; íd., Iglesia y Estado, régimen jurídico de sus relaciones, Madrid, 1980; id., Derecbo eclesiástico del Estado español, Pamplona, 1980; D. Llamazares y G. Suárez Pertierra, «El fenómeno religioso en la nueva Constitución española. Bases de su tratamiento», en Revista de la Facultad de Derecho de la Universidad Complutense de Madrid, núm. 61, págs. 7-34; A. de la Hera, Pluralismo..., cit., páginas 59-91. 
que este derecho - como el conjunto de las declaraciones de derechos- debe ser interpretado a la luz de los principios básicos que inspiran nuestra Constitución. El tratamiento del hecho religioso se reconduce - como recuerda Viladrich 9 - «a la soberanía nacional que reside en el pueblo español» (art. 1.2), que expresa como valores superiores de su orden jurídico «la libertad, la justicia, la igualdad y el pluralismo político» (art. 1.1) y exige de los poderes públicos que promuevan «las condiciones para que la igualdad y la libertad del individuo y los grupos en que se integra sean realeș y efectivas...» (art. 9.2). En coherencia con estos principios, la Constitución declara que los españoles «son iguales ante la ley, sin que pueda prevalecer discriminación alguna por razón de... religión...» (art. 14).

La regulación del fenómeno religioso en la Constitución vigente, en los términos antes expresados, supone una ruptura total con los principios inspiradores de la legislación del régimen político anterior. Baste recordar el principio II del Movimiento Nacional, en el que se decía que «la nación española considera como timbre de honor el acatamiento a la Ley de Dios según la doctrina de la Santa Iglesia Católica, Apostólica y Romana, única verdadera y fe inseparable de la conciencia nacional, que inspira su legislación»; la fuerza vinculante de este principio aparece ratificado por el artículo 3 de dicha ley fundamental, que establecía que las leyes y disposiciones de cualquier clase que se opusieran a dicho principio serían nulas.

El contraste entre la regulación de la libertad religiosa en nuestra Constitución y la legislación del régimen político precedente es manifiesta. La Constitución de 1978, al regular el fenómeno religioso, se inspira en las declaraciones de los derechos humanos que a partir del siglo xvirr han sido formulados por los Estados modernos y por los organismos internacionales y que, tras una precisa elaboración doctrinal, sirven hoy de fundamento del Derecho eclesiástico moderno, concebido como legislatio libertatis. Por el contrario, la antetior legislación se basaba en los principios del Derecho público eclesiástico que inspiran - desde el punto de vista de la Iglesia católica- las relaciones Iglesia-Estado y presentan como modelo de dichas relaciones el Estado confesional católico ${ }^{10}$.

Según esta concepción, el Estado se somete a la doctrina católica -cláusula límite de la validez de sus leyes-, y, por esta razón, el fenómeno religioso deberá regularse de acuerdo con dicha doctrina. Así ha ocurrido con la Ley de Libertad Religiosa de 1967, que se inspira en la declaración Dignitatis bumanae del Concilio Vaticano II, justificando el reconocimiento de este derecho civil en base a la declaración conciliar, lo que ha permitido sostener la

${ }^{9}$ Cfr. P. J. Viladrich, «Los principios informadores del Derecho eclesiástico español», en Derecho eclesiástico del Estado español, cit., pág. 215.

${ }_{10}$ Véase J. Calvo, Teoría general del Derecbo público eclesiástico, Santiago, 1968; E. Fogliasso, «I principi del Diritto Pubblico Ecclesiastico nel Messaggio di Franco alle Cortes per il nuevo Concordato Spagnolo», en Salesianum, núm. 17, 1965, págs. 69-91; íd., «El nuevo Concordato español y el Derecho público eclesiástico», en Revista Española de Derecho Canónico, núm. 9, 1954, págs. 43-63; Hera-Munier, «Le Droit Public Ecclésiastique à travers ses définitions», en Revue de Droit Canonique, núm. 14, 1964; V. Reina, Lecciones de Derecho público eclesiástico, pro manuscrito, Pamplona, 1967. 
pervivencia de la confesionalidad del Estado, compatible — desde esa perspectiva - con la vigencia del derecho civil de libertad religiosa ${ }^{11}$.

La solución constitucional difiere radicalmente de este planteamiento. E1 fundamento del derecho de libertad religiosa se encuentra en la concepción de un Estado basado en la soberanía popular, que reconoce como valores superiores de su orden jurídico la libertad, la justicia, la igualdad y el pluralismo político. En congruencia con estos presupuestos, la Constitución «contempla formalmente el hecho religioso en su estricta dimensión de factor social sometido a un tratamiento de índole jurídico-civil ${ }^{12}$, sin ningún condicionante proveniente de una confesión religiosa. El hecho religioso se considera así en cuanto hecho social, no en cuanto religioso, que exige una regulación jurídica.

Tanto desde un punto de vista individual como colectivo, la Constitución reconoce el derecho de libertad religiosa. Un derecho basado en los principios que inspiran la Constitución y exento, por tanto, de cualquier condicionante -ajeno a la propia soberanía popular- de carácter confesional. Esto significa que la interpretación de este derecho no debe hacerse a la luz de los principios de la doctrina católica —como era obligado en la legislación del régimen anterior-, sino de acuerdo con los principios que inspiran la Constitución ${ }^{13}$.

\section{La libertad religiosa como principio constitucional de regulación del factor religioso}

La libertad religiosa es entendida frecuentemente como teconocimiento del derecho fundamental de los ciudadanos a profesar las creencias religiosas libremente elegidas o, simplemente, a no profesar ninguna. Esta libertad jurídica, referente a un sector de los derechos humanos reconocidos a los ciudadanos, no agota el sentido específico de la libertad religiosa; además de la acepción de la libertad religiosa como derecho subjetivo, tiene otra, quizá más amplia y definitoria, como Principio de organización social y de configuración cívica que contiene una idea o definición de Estado ${ }^{14}$.

Como antes se ha expuesto, la Constitución de 1978 ha mantenido una posición original ante el hecho religioso. Abandonando posiciones partidarias que, con anterioridad, habrían propiciado la conversión de la regulación del hecho religioso en una cuestión problemática, la Constitución ha rechazado tanto la fórmula de la confesionalidad —de viejo arraigo en nuestras Constituciones- como la fórmula laicista y separatista que, de forma innovadora, asumió la Constitución de la II República. La nueva Constitución optó por el principio de libertad religiosa en un loable intento de superación de la confe-

${ }^{11}$ Véanse A. de la Hera, «Confesionalidad del Estado y...», cit.; J. Pérez Llantada, La libertad religiosa en España y en el Vaticano II, Madrid, 1974; Suárez Pertierra, Libertad religiosa y..., cit.

${ }_{12}$ P. J. Viladrich, «Los principios...», cit., pág. 214.

${ }^{13}$ Para la interpretación del art. 16 de la Constitución es oportuno tener en cuenta los antecedentes, precedentes históricos y Derecho comparado que han sido utilizados para la elaboración del texto; véase O. Alzaga, La Constitución española de 1978. Comentario sistemático, Madrid, 1978, pág. 189.

${ }_{14}$ Cfr. Viladrich, op. cit., pág. 214. 
sionalidad - llevada a posiciones extremas en el régimen anterior- y del laicismo, con la finalidad de procurar hallar una solución razonable a la llamada «cuestión religiosa», que, históricamente, ha tendido a discriminar y dividir a la sociedad española. Como ha afirmado Viladrich, «la Constitución española quiebra la relación entre confesionalidad y laicidad, estableciendo una nueva alternativa: el primer principio definidor del Estado en materia eclesiástica será el principio de libertad religiosa, que sustituye en este prioritario papel al de confesionalidad, propio de la mayor parte de nuestra historia constitucional y del período franquista, y al de laicidad según la versión de la Constitución republicana de $1931 \gg^{15}$.

Este nuevo planteamiento tiene un indudable interés para la interpretación correcta de la consideración del fenómeno religioso por parte del Estado. Frente a las posiciones parciales que entrañan tanto la confesionalidad como la laicidad, el principio de libertad religiosa reclama la primacía en la regulación del fenómeno del hecho religioso. Allí donde está vigente el principio de confesionalidad y reconocida, simultáneamente, la libertad religiosa ocurre que, en caso de conflicto, prevalece la confesionalidad sobre la libertad. La Ley de Libertad Religiosa de 1967 nos da la pauta de esa conducta y ratifica el aserto anterior al establecer como límite del derecho de libertad religiosa a la propia confesionalidad del Estado ${ }^{16}$. El mismo supuesto se reproduce cuando la laicidad constituye el principio informador del Estado en la regulación del hecho religioso. La discrepancia entre los artículos 26 y 27 de la Constitución de 1931 refleja claramente la subordinación del derecho de libertad religiosa al principio de laicidad, establecido en dicha Constitución con un contenido claramente beligerante respecto al propio derecho de libertad religiosa ${ }^{17}$.

Ciertamente, la asunción por parte del Estado del principio de libertad religiosa supone el reconocimiento pleno y el consiguiente respeto del derecho de libertad religiosa. Al adoptar este principio, la Constitución de 1978 atribuye al Estado una posición más independiente $\mathrm{y}$, por supuesto, menos sectaria respecto a las diferentes confesiones religiosas y le impone la obligación de

${ }^{15}$ Ob. cit., pág. 251. En la exposición de este principio seguiremos preferentemente el excelente estudio que este autor hace en la obra citada.

${ }_{16}$ «El ejercicio del derecho a la libertad religiosa, concebido según la doctrina católica, ha de ser compatible en todo caso con la confesionalidad del Estado español proclamada en sus Leyes Fundamentales» (Ley 44/1967, de 28 de junio, regulando el ejercicio del derecho civil a la libertad en materia religiosa, art. $2 .^{\circ}$ ).

${ }_{17}$ El art. 27 de la Constitución de 1931 declara: «La libertad de conciencia y el derecho de profesar y practicar libremente cualquier religión quedan garantizados en el territorio español, salvo el respeto debido a las exigencias de la moral pública»; previamente, sin embargo, el art. 26, reflejando una actitud claramente beligerante, ordena la disolución de «aquellas órdenes religiosas que estatutariamente imponga, además de los tres votos canónicos, otro especial de obediencia a autoridad distinta de la legítima del Estado: sus bienes serán nacionalizados y afectados a fines benéficos y docentes». Para las demás asociaciones se dispone su sometimiento a una ley especial en la que se establecerá: «La incapacidad de adquirir y conservar, por sí o por persona interpuesta, más bienes que los que, previa justificación, se destinen a su vivienda o al cumplimiento de sus fines privativos... La prohibición de ejercer $\mathrm{l}_{a}$ industria, el comercio o la enseñanza... La obligación de rendir anualmente cuentas al Estado de la inversión de sus bienes en relación con los fines de la asociación. Los bienes de las órdenes religiosas podrán ser nacionalizados.» 
respetar plenamente el derecho de los ciudadanos a profesar y practicar sus creencias. Pero, al mismo tiempo, considerado el hecho religioso en cuanto hecho social, el Estado no puede permanecer pasivo o indiferente ante el mismo, sino que ha de favorecer y facilitar la libertad religiosa, ya que «corresponde a los poderes públicos promover las condiciones para que la libertad y la igualdad del individuo y de los grupos en que se integra sean reales y efectivas, remover los obstáculos que impidan o dificulten su plenitud y facilitar la participación de todos los ciudadanos en la vida política, económica, cultural y social» ${ }^{18}$.

Esta actitud positiva del Estado ante el factor religioso no está en contradicción con el artículo 16.3 de la Constitución, que declara: «Ninguna confesión tendrá carácter estatal.» Esto significa que el Estado no se identifica con ninguna religión concreta, pero de ningún modo que el Estado deba mostrarse indiferente u hostil -característica del Estado laico decimonónico- ante el hecho religioso. La aconfesionalidad del Estado es compatible - como dispone el mismo artículo 16.3 - con la obligación constitucional impuesta al Estado de cooperar con las confesiones religiosas: «Los poderes públicos tendrán en cuenta las creencias religiosas de la sociedad española y mantendrán las consiguientes relaciones de cooperación con la Iglesia católica y las demás confesiones.» El Estado, si bien debe mantener una actitud neutral y no partidaria ante cada una de las confesiones religiosas, debe adoptar, al mismo tiempo, una actitud positiva ante el hecho religioso, protegiendo los derechos individuales de los ciudadanos y de los grupos confesionales y favoreciendo su desarrollo mediante las oportunas relaciones de cooperación.

La Constitución, en resumen, ha optado por el principio de libertad religiosa, desestimando fórmulas antes vigentes en nuestro sistema constitucional como son la confesionalidad y la laicidad. El Estado, al declararse aconfesional, renuncia a efectuar una elección religiosa, un acto de fe para el cual es incompetente; reconoce y respeta el pluralismo religioso $\mathrm{y}$, por tanto, todas las opciones religiosas en régimen de igualdad. Esta actitud, sin embargo, es compatible con una postura positiva, reconociendo lo religioso como un factor social específico que el Estado no debe ignorar, sino favorecer a través de las oportunas relaciones de cooperación con las distintas confesiones religiosas, de acuerdo con lo dispuesto en la Constitución.

\section{El reconocimiento constitucional de las confesiones religiosas}

El derecho de libertad religiosa, garantizado en nuestra Constitución, se refiere a los individuos y a las comunidades. El derecho de los ciudadanos a profesar y practicar libremente sus creencias religiosas se amplía al quedar garantizado, en coherencia con el artículo 26, el derecho de asociación religiosa. Los ciudadanos pueden asociarse con la intención de realizar de modo institucional aspectos de su creencia religiosa y de acuerdo con sus propios criterios de organización y régimen.

${ }^{18}$ Art. 9.2. 
Estos colectivos, manifestaciones del carácter social del hecho religioso y expresión del pluralismo democrático, están presentes en la sociedad, y la Constitución garantiza su libertad sin más limitaciones que el mantenimiento del orden público protegido por la ley. El reconocimiento de este hecho colectivo podría haber quedado igualmente garantizado a través del artículo 22 de la Constitución, que reconoce el derecho de asociación, práctica usual en otras legislaciones.

No ocurre así en nuestra Constitución, que reconoce el derecho de asociación religiosa en texto independiente y previo al que regula el derecho de asociación con carácter general. Esta individualización del asociacionismo religioso y su segregación del derecho de asociación común no constituye una excepción en el texto constitucional. «Las Constituyentes -explica Alzagaoptaron por reconocer en artículos distintos el derecho de asociación que aquí tratamos (art. 22), el derecho de fundación (art. 34) y el derecho de sindicación (art. 28), aunque en teoría habría sido preferible refundirlos en un mismo precepto, como de hecho ocurría, por ejemplo, en el artículo 39 de la Constitución española de 1931, por no poner sino un ejemplo. Sin embargo, en nuestro reciente proceso constituyente ha existido una especial preocupación porque el reconocimiento y tratamiento constitucional de los grandes derechos y libertades fuera explícito e incluso con frecuencia rico en detalles» ${ }^{19}$.

Aunque Alzaga no lo cite expresamente, entre los derechos y libertades que la Constitución desea resaltar de forma explícita figura el derecho de asociación religiosa. Este tratamiento especial se hace notar, incluso, al calificar a las asociaciones religiosas de una manera explícita y «rica en detalles» - según la propia expresión del autor- como confesiones religiosas. No habría sido necesario, pero expresa de forma inequívoca la intención del legislador de singularizar el asociacionismo religioso.

La mención explícita de las confesiones religiosas y su regulación singular no significa, en modo alguno, una discriminación del propio derecho asociativo. Como explica Viladrich, «al definir a todos estos grupos como confesiones, el Estado lo único que ofrece es una estructura jurídica a la que bacer centro de imputaciones de derechos y deberes civiles. Sobre su régimen interno organizativo y sobre su contenido dogmático-religioso el Estado se abstiene por completo de cualquier pretensión de reestructuración orgánica o de juicio de valor sobre su verdad religiosa. Es la libre concurrencia, iniciativa y capacidad fundacional y organizativa de los ciudadanos y de los grupos, en una sociedad democrática, la que origina y mantiene, modifica o extingue aquellos contenidos internos -orgánicos o dogmáticos- de dichos colectivos religiosos. Al no establecer prejuicios discriminatorios sobre su creencia y al someterlos sin excepción a los principios de libertad, justicia, igualdad y pluralismo, que inspiran todo el orden público estatal (art. 1), el concepto de confesión es una estructura jurídica civil, igualitaria, que no tiene otra función que resolver la personalidad jurídica de los sujetos colectivos de derecho eclesiástico a la luz de los principios constitucionales de libertad religiosa y de laicidad del Estado" ${ }^{20}$.

${ }^{19}$ O. Alzaga, ob. cit., pág. 230.

${ }^{20}$ Ob. cit., pág. 223. 


\section{La igualdad constitucional de las confesiones}

Queda dicho que la Constitución, al calificar a todas las asociaciones religiosas con el apelativo confesiones, crea una estructura jurídica común e igual para todas ellas. No existe, pues, una discriminación jurídica ni una valoración, por parte del Estado, de los contenidos dogmáticos-religiosos de los grupos religiosos actuantes en la sociedad española. A esta igualdad jurídica se suma la neutralidad del Estado ${ }^{21}$ al declarar que ninguna confesión tendrá carácter estatal ${ }^{22}$. La igualdad jurídica se ratifica, así, con esta igualdad estimativa en el contexto político al abdicar el Estado de formular una declaración de preferencia o asunción de una verdad religiosa en perjuicio de las demás, que vendrían a ser consideradas confesiones de segundo orden. El Estado renuncia a pronunciarse sobre una cuestión que es propia de los individuos y coherente con el legítimo pluralismo reconocido en la Constitución.

La atribución de una estructura jurídica común para todas las confesiones. y la renuncia, por parte del Estado, a emitir un juicio de valor acerca de la verdad de cada creencia religiosa, supone el reconocimiento constitucional de la igualdad de las confesiones ante la ley civil. Igualdad de derechos y obligaciones, igualdad jurídica de todas las confesiones que es compatible con la diversidad de creencias, organización y régimen de cada una de ellas, porque es preciso no confundir igualdad con uniformidad ${ }^{23}$.

El Estado, en efecto, no tiene la pretensión de crear una estructura jurídica a la que tengan que adaptarse las confesiones en su organización, régimen y relaciones con sus miembros. Por el contrario, la Constitución respeta las peculiaridades propias de cada confesión y se limita a ofrecerles una titularidad jurídica en el ordenamiento del Estado como sujetos colectivos de la libertad religiosa y centros de imputación de derechos y deberes civiles.

«La Constitución de 1978 -afirma Viladrich - no persigue, al darles la misma libertad de reconocimiento y protección mediante el común denominador conceptual de confesiones, uniformarlas en sus legítimas y reales diferencias de estructura, jerarquía, credo y raigambre histórico o actual. Dicho de otro modo: el concepto de confesión sirve no sólo para no discriminarlas ante el derecho del Estado por razones religiosas (confesionalidad estatal), sino también para no uniformarlas ante ese derecho por razones que, aunque estatales, impliquen una intromisión en la autonomía y en la peculiaridad de lo religioso (jurisdiccionalismo estatal)» ${ }^{24}$.

El reconocimiento legal de los colectivos religiosos, previsto en la Constitución, toma como punto de partida la no injerencia en la conformación interna de las confesiones y en su plural variedad orgánica, jurídica o sociológica. El Estado asume ese pluralismo, y al otorgarles un status jurídico en su orde-

${ }^{21}$ Cfr. J. Carvajal, «Principios informadores del actual régimen español de relaciones entre la Iglesia y el Estado», en Iglesia y Estado en España. Régimen jurídico de sus relaciones, Madrid, 1980, pág. 42.

${ }^{22}$ Art. 16.3.

23 P. J. Viladrich, ob. cit., pág. 223.

${ }^{24}$ Ob. cit., pág. 225. 
namiento sin discriminaciones, tampoco pretende imponerles -en virtud de la igualdad - una uniformidad que altere o modifique sus legítimas peculiaridades.

La advertencia reiterada de que no debe confundirse igualdad con uniformidad comprende tanto la no injerencia del Estado en los contenidos propios de cada confesión como la reducción a un tratamiento uniforme de las relaciones del Estado con las confesiones. La real diversidad de cada confesión debe traducirse en una diversidad de relaciones con cada confesión, teniendo en cuenta su propia especificidad.

Como afirma Francesco Ruffini: «El tratar, como ya hacía el viejo Ahrens, de manera igual relaciones jurídicas desiguales es tan injusto como el tratar de modo desigual relaciones jurídicas iguales. Todavía se podría resaltar que hay aquí una paridad entendida falsamente, a saber: la de la igualdad absoluta, abstracta, matemática y otro sentido de la paridad, esta vez en su acepción justa, que es aquella consistente en la igualdad relativa, concreta, jurídica; puesto que, como señala acertadamente Kahl, el verdadero principio no es el de a cada uno lo mismo, sino a cada cual lo suyo» ${ }^{25}$.

La igualdad de las confesiones - proclamada por la Constitución - no entraña, por tanto, un tratamiento uniforme de todas ellas, pues ello podría suponer una injerencia indebida en su propia organización y régimen interno $y$, en definitiva, una desigualdad sustancial contraria a la Constitución. En este sentido, el establecimiento de relaciones de cooperación con las distintas confesiones - tema que abordaremos más adelante - no puede ser impuesto uniformemente a todas las confesiones en base a una pretendida igualdad, pues, mientras unas confesiones pueden desear establecer estas relaciones, es posible que otras las rechacen por repugnar a la propia naturaleza de la confesión. Incluso, aceptando tales relaciones, es posible que el contenido sea diverso en función de las aspiraciones y necesidades propias de cada confesión. Pretender un régimen jurídico uniforme de estas relaciones de cooperación puede constituir un grave atentado a la identidad propia de cada confesión y, en consecuencia, a un trato desigual como resultado de confundir la igualdad jurídica con la uniformidad jurídica ${ }^{26}$.

La realidad jurídica debe acomodarse a la realidad plural y varia de las confesiones, respetando sus legítimas peculiaridades y apreciando su inserción en la sociedad española como hecho social, que es, en definitiva, lo que el

${ }^{25} \mathrm{~F}$. Ruffini, Corso di diritto ecclesiastico italiano. La libertà religiosa como diritto pubblico subiectivo, Turín, 1924, trad. y cit. de Viladrich, ob. cit., pág. 285.

${ }^{26}$ Mantienen una opinión contraria Llamazares y Suárez Pertierra: «Su concreción ha de ser obra de la jurisprudencia, que, en términos precisos, debe situarse ante la elección entre la clásica igualdad de proporcionalidad y un criterio moderno y, en nuestra opinión, más adecuado, según el cual deben tenerse en cuenta todos los factores sociales en orden a la relación de concurrencia entre las confesiones, tales como el grado de cultura e instrucción de los individuos, el desarrollo de las ideas y las garantías formadas contra toda coacción o, en definitiva, nivel de desarrollo de los ciudadanos. Si se tiene en cuenta que el sentido último del precepto consiste en convertir la igualdad meramente formal en igualdad sustancial, deben ser obviadas aquellas concesiones de facultades supletorias a un determinado grupo social, que, fundamentadas en desigualdad de hecho, contribuirán a su perpetuación» ( $\ll \mathrm{E}$ l fenómeno religioso...», cit., págs. 20-21). 
Estado debe proteger y regular jurídicamente. El Estado renuncia a valorar la confesión en su dimensión religiosa —-creencias, organización, régimen-, pero está obligado a valorarla como factor social; por tanto, es coherente afirmar que la neutralidad del Estado «no está reñida, como es lógico, con el reconocimiento de la realidad social de unas religiones que, por razones históricas, culturales $\mathrm{y}$, sobre todo, de proporción numérica de fieles, tengan un mayor arraigo y peso en la sociedad ${ }^{27}$.

Reconduciendo lo dicho hasta ahora se pueden proponer las siguientes conclusiones: a) la igualdad es compatible con el reconocimiento de las legítimas peculiaridades de las diversas confesiones; $b$ ) el límite de este reconocimiento de lo específico de cada confesión lo constituye el principio de no discriminación; c) el objeto de la no discriminación no consiste en la prohibición de la presencia en el derecho del Estado del reconocimiento de las reales e irreductibles peculiaridades del factor religioso; $d$ ) la exigencia de concebir la no discriminación como una exigencia de uniformidad provocaría la quiebra de la libertad religiosa.

\section{La mención explícita de la Iglesia católica}

A la luz de estas conclusiones se puede proceder a la interpretación del significado de la mención explícita que de la Iglesia católica hace el texto constitucional. Esta mención -que suscitó una viva polémica en su día- es interpretada de modo diverso por la doctrina. Desde una determinada perspectiva, esta mención se valora como una confesionalidad sociológica del Estado ${ }^{28}$; desde otra posición, se rechaza tajantemente esa interpretación y se explica como resultado del trato específico del factor religioso y como un reconocimiento del arraigo de la Iglesia católica en la sociedad española ${ }^{29}$.

En efecto, para Llamazares y Suárez Pertierra: «No sería difícil trascender desde esta realidad a una especie de confesionalidad atenuada y no expresa del Estado español basada en el factor social, que no es sino el fundamento de la llamada, por contraposición a la confesionalidad doctrinal o valorativa, confesionalidad sociológica del Estado... La Constitución instaura un sistema no unitario de tratamiento de las confesiones. Sobre la base del substrato sociológico trascendido a lo institucional, el nuevo régimen jurídico permite plantear la persistencia de un régimen dualista de relaciones con el fenómeno religioso en perjuicio del concepto constitucional de confesión» ${ }^{30}$.

Una opinión contraria es mantenida por Carvajal al afirmar: «No hay, pues, a nuestro juicio, ninguna confesionalidad implícita, sino el reconocimiento de un hecho sociológico - el peso de la Iglesia católica en España- y otro jurídico - su personalidad internacional-, sin que ninguno de ellos comporte una verdadera discriminación en relación con otras confesiones religiosas, aun-

${ }^{27} \mathrm{~J}$. Carvajal, ob. cit., págs. 43-44.

${ }^{28}$ Cfr. A. Prieto, «Las confesiones religiosas no católicas», en Iglesia y Estado..., cit., pág. 277; D. Llamazares y Suárez Pertierra, ob. cit., págs. 33 y 34.

${ }_{30}$ Cfr. J. Carvajal, ob. cit., pág. 45; P. J. Viladrich, ob. cit., págs. 290 y sigs.

${ }^{30} \mathrm{Ob}$. cit, págs. 33 y 34 . 
que sí en trato distinto, como corresponde a la naturaleza objetiva de las cosas y de los hechos, y no a una preferencia o valoración subjetiva por parte del Estado» ${ }^{31}$.

Esta postura es mantenida también por Viladrich, que, tras negar que tal mención constituya un reconocimiento formal o sociológico del Estado; ya que, según el mismo artículo de la Constitución, «ninguna confesión tendrá carácter estatal», agrega que la mención explícita de la Iglesia católica constituye «un ejemplo, ciertamente constitucional, de trato específico en atención a la enorme extensión sociológica, tradición y arraigo histórico, y complejidad orgánica y jurídica de la Iglesia católica en comparación con las demás confesiones religiosas. Ahora bien: en el texto constitucional ese trato específico se limita, en realidad, a la mención singular de la Iglesia católica, al aludirla con su apellido propio. Sin embargo, debemos indicar que con respecto al contenido, en que debe concretarse ese trato específico, no hay mandato constitucional alguno como no sean las consiguientes relaciones de cooperación, las cuales también se predican para todas las demás confesiones» ${ }^{32}$.

Nuestra postura al respecto es clara. La Constitución rechaza la fórmula confesional terminantemente y sin ambages. No cabe hablar, por tanto, de una confesionalidad atenuada o solapada. «Ninguna confesión tendrá carácter estatal»-dice la Constitución-y, por tanto, ni formal, ni sustancialmente, ni tampoco sociológicamente puede admitirse la existencia de una confesión estatal. El texto constitucional es tajante y no admite modulaciones ni mati-. zaciones.

La interpretación del significado que pueda tener la mención explícita de la Iglesia católica hay que buscarla, por tanto, por otros caminos. En nuestra opinión el significado aparece claramente expuesto en el texto constitucional: «... y mantendrán las consiguientes relaciones de cooperación con la Iglesia católica y las demás confesiones.» La Constitución insta a los poderes públicos - con carácter imperativo- a adoptar una postura activa y positiva en relación con las confesiones religiosas, imponiéndoles la obligación de establecer relaciones de cooperación con los mismos.

Se trata de una obligación genérica de los poderes públicos con todas las confesiones religiosas, incluida, por tanto, la Iglesia católica. Esta mención, que no modifica la posición jurídica de la Iglesia ante el Estado, hay que interpretarla a la luz del párrafo anterior del artículo 16.3: «Los poderes públicos tendrán en cuenta las creencias religiosas de la sociedad española...» La Constitución exige a los poderes públicos que valoren el factor social religioso $\mathrm{y}$, en consecuencia, precisen el arraigo de las diferentes confesiones. En función de este conocimiento mantendrán relaciones de cooperación con las diversas confesiones. Al mencionar explícitamente a la Iglesia católica, la Constitución releva a los poderes públicos de probar el arraigo de la Iglesia católica. El notorio arraigo de la Iglesia católica en la sociedad española es reconocido expresamente en el texto constitucional, relevando así a los poderes públicos de una valoración que deberán hacer respecto de otras confesiones.

31 Ob. cit., pág. 45.

${ }^{32}$ Ob. cit., págs. 292-293. 
Lo notorio no necesita ser probado. Esto es lo único que hace la Constitución respecto de la Iglesia católica. Esto no significa situación privilegiada, confesionalidad encubierta o discriminación de las demás confesiones. Es, simplemente, el reconocimiento de un hecho social, de su especificidad como confesión con vigencia secular y actual en la sociedad española. La Constitución se limita a reconocer explícitamente lo que sabe y conoce cualquier ciudadano. Como ha dicho el diputado Oscar Alzaga en la Comisión del Congreso de los Diputados, con motivo de la discusión de este artículo de la Constitución: «Solamente hemos sentado la no confesionalidad, y rechazo, una vez más; que de forma solapada vengamos a establecer una confesionalidad, y sí un sano principio de entendimiento, que es tanto como acabar con la lucha, con los planteamientos beligerantes en materia que afecta a la confesión religiosa» ${ }^{33}$.

\section{Las relaciones de cooperación del Estado con las confesiones}

La libertad religiosa, que garantiza la Constitución, comprende el reconocimiento del pluralismo religioso, la igualdad ante la ley de todas las confesiones, la neutralidad o aconfesionalidad del Estado y la apreciación de la especificidad propia de toda confesión, rechazando así el uniformismo jurídico, tan contrario a la libertad como a la igualdad religiosa.

La neutralidad del Estado ante cada confesión, al reconocer la Constitución que ninguna confesión tendrá carácter estatal, no equivale a la indiferencia o pasividad ante el factor social religioso o a incomunicación del Estado con las propias confesiones religiosas. La obligación constitucional que recae sobre los poderes públicos de mantener relaciones de cooperación con las confesiones religiosas, lejos de la actitud beligerante o indiferente del laicismo decimonónico, contiene, en nuestra opinión, los siguientes aspectos: a) el deber de los poderes públicos de abrir cauces de comunicación con las confesiones religiosas; b) el deber de prestar la colaboración oportuna a las confesiones religiosas - en cuanto factor social - para que puedan cumplir sus propios fines; c) el deber de procurar una normativa jurídica pactada con cada confesión, acorde con las características y fines propios.

Estas relaciones, elevadas al rango constitucional, serán de cooperación, excluyendo, así, cualquier incertidumbre respecto a la naturaleza del sistema eclesiasticista establecido por la Constitución. Ni sistemas de unión entre Iglesias y Estado, ni sistemas de separación absoluta entre el Estado y las confesiones. El sistema de cooperación expresa el tipo de relación entre instituciones que, siendo distintas por su naturaleza y fines, han de coexistir, sin confundirse, en un régimen de armónica colaboración.

La cooperación, por tanto, abarca los siguientes aspectos:

a) La participación de cada confesión en la elaboración de su status jurídico en el derecho del Estado; esta participación exige la comunicación con los poderes públicos y el entendimiento bilateral que haga compatible el reco-

${ }_{33}$ O. Alzaga, "Intervención en la Comisión del Congreso», 18 de mayo de 1978 (Diario de Sesiones, núm. 69, pág. 2482). 
nocimiento de los datos diferenciales y el arraigo real en la sociedad española de cada confesión con las normas generales y comunes del Estado, reguladoras del fenómeno religioso.

b) La posibilidad de establecer conciertos Estado-confesión en relación con aquellas actividades que contribuyan al bien común y revistan la naturaleza de función social, dirigida o promovida por cada confesión.

En conclusión, el principio de cooperación significa «la constitucionalización del común entendimiento, bilateral o plurilateral, que han de tener las relaciones entre los poderes públicos y las confesiones en orden a la elaboración de su status jurídico específico y a la regulación de su contribución al bien común ciudadano» ${ }^{34}$.

\section{DESARROLLO LEGISLATIVO}

\section{La Ley Orgánica de Libertad Religiosa}

Los preceptos constitucionales reguladores del factor religioso han sido desarrollados, posteriormente, por la Ley Orgánica 7/1980, de 5 de julio, de Libertad Religiosa. Consta de ocho artículos, dos disposiciones transitorias, una derogatoria y una final.

La LOLR, que desarrolla el artículo 16 de la Constitución en relación con el artículo 14, regula el derecho a la libertad religiosa y establece el régimen legal de las entidades religiosas. Garantiza el derecho fundamental a la libertad religiosa y de culto, la igualdad y no discriminación y la aconfesionalidad del Estado (art. 1); los derechos de los ciudadanos en materia religiosa y de las confesiones (art. 2); regula los límites de la libertad religiosa (art. 3); la protección jurídica del derecho de libertad religiosa (art. 4); la personalidad jurídica de las confesiones (art. 5); la autonomía de las confesiones (art. 6); las relaciones de cooperación entre el Estado y las confesiones (art. 7) y la creación de la Comisión Âsesora de Libertad Religiosa (art. 8). Dos disposiciones transitorias regulan el reconocimiento de la personalidad jurídica y del patrimonio de las entidades religiosas que gozaren de ella con anterioridad a la entrada en vigor de dicha Ley. Una disposición derogatoria de la Ley 44/1967, de 28 de junio, y una disposición final, autorizando al Gobierno para dictar las disposiciones necesarias para la organización y funcionamiento del Registro y de la Comisión Asesora de Libertad Religiosa, completan el contenido de la Ley Orgánica ${ }^{35}$.

La LOLR sienta las bases del régimen común de las confesiones religiosas con una intencionada generalidad e inconcreción. La Ley fue presentada inicialmente como «una norma marco, caracterizada por su flexibilidad, con

${ }^{34}$ P. J. Viladrich, ob. cit., pág. 308.

${ }^{35}$ Para una información doctrinal más completa de esta ley véase $\mathrm{C}$. Corral, «La Ley Orgánica española de Libertad Religiosa», en Revista Española de Derecbo Canónico, núm. 37, enero-agosto 1981, págs. 59-117; J. Pérez-Llantada, «Hacia un análisis jurídico de la Ley Orgánica de Libertad Religiosa», en Boletín de la Facultad de Derecho. Universidad Nacional de Educación a Distancia, núms. 6-7, 1981, págs. 5-18. 
el objeto de que pudieran tener cabida las múltiples formas de manifestación religiosa». La supresión de la denominación marco -aceptando una enmienda del Grupo Parlamentario Socialista de Cataluña- no eliminó el espíritu de la Ley de mantener unos cauces amplios y flexibles ante el factor religioso.

Una de las características más significativas de la LOLR es la concreción de las relaciones de cooperación, de que hace mención el artículo 16.3 de la Constitución, a través de Acuerdos o Convenios de cooperación del Estado con las Iglesias, confesiones y comunidades religiosas. La LOLR establece así los cauces por donde han de discurrir las relaciones de cooperación que constituyen un mandato constitucional para los poderes públicos. Esta solución normativa permite aventurar una interesante cuestión jurídica acerca de la armonización del marco legal común y los acuerdos específicos con las diferentes confesiones.

Esta cuestión ya ha sido denunciada por la doctrina, por lo que se refiere a la coexistencia de la propia LOLR y los Acuerdos del Estado con la Santa Sede. En este orden de cosas, el problema fundamental que plantea la Ley es que, por una parte, pretende ser el marco legal común para el régimen jurídico de todas las confesiones, incluida la católica, y por otra, el hecho de que su promulgación es posterior a la firma de los Acuerdos, ya vigentes, con la Santa Sede. Este hecho puede contribuir a una interpretación amplia del estatuto jurídico de las demás confesiones; en cambio, «por lo que a la Iglesia se refiere, la ley se sitúa en un plano inconcreto entre la función de norma marco de unos acuerdos ya vigentes y la de norma de ejecución de los mismos acuerdos acerca de materias ya contempladas en ellos. Esta doble y difícil-. mente armonizable función provoca un desajuste entre la Ley Orgánica y los Acuerdos, con la consecuencia de algunas contradicciones, por ejemplo, en materia de personalidad jurídica civil de los entes eclesiásticos» ${ }^{36}$.

El rango jurídico de Tratados internacionales que, de acuerdo con el procedimiento de aprobación y la opinión más común de la doctrina, le corresponde a los Acuerdos plantea, ciertamente, un problema de colisión de normas que será necesario intentar armonizar. En cualquier caso, éste no es un supuesto aislado en nuestro Derecho actual. La Constitución ha quebrado el centralismo y el uniformismo jurídico impuesto en nuestro país a lo largo del siglo pasado. El reconocimiento del carácter autonómico de determinados entes territoriales, institucionales y sociales; el origen pacticio y estatutario de ciertas normas previstas en nuestra Constitución permiten aventurar la construcción de un ordenamiento jurídico más variado y plural que el precedente y, al mismo tiempo, más acorde con nuestro derecho histórico.

El pluralismo de fuentes normativas planteará problemas complejos de armonización en orden a su interpretación y aplicación. El Derecho eclesiástico nacido de la Constitución no va a ser una excepción. Los acuerdos con las confesiones religiosas que se suscriban, a tenor del artículo 7 de la LOLR, van a generar un orden jurídico específico para cada confesión religiosa. Aunque su marco legal común será la Constitución y la Ley Orgánica, es evidente que el reconocimiento de las peculiaridades propias de cada confesión provocará

${ }^{36}$ P. Lombardía, ob. cit., pág. 204. 
situaciones de colisión normativa, que habrán de ser resueltas en sede jurídica con prudencia y sensibilidad. Aparte de la solución última, cuya competencia corresponde a los tribunales, ha sido un acierto la creación en la propia LOLR de una Comisión Asesora de Libertad Religiosa que, por su composición y competencia, puede prestar un excelente servicio a los fines reseñados.

\section{La creación de la Comisión Asesora de Libertad Religiosa}

El artículo. 8 de la LOLR establece lo siguiente: «Se crea en el Ministerio de Justicia una Comisión Asesora de Libertad Religiosa compuesta de forma paritaria y con carácter estable por representantes de la Administración del Estado, de las Iglesias, confesiones y comunidades religiosas o Federaciones de las mismas, en las que, en todo caso, estarán las que tengan arraigo notorio en España, y por personas de reconocida competencia, cuyo asesoramiento se considere de interés en las materias relacionadas con la presente Ley. En el seno de esta Comisión podrá existir una Comisión Permanente, que tendrá también composición paritaria. A dicha Comisión corresponderán las funciones de estudios, informes y propuesta de todas las cuestiones relativas a la aplicación de esta Ley, y particularmente, y con carácter preceptivo, en la preparación y dictamen de los acuerdos o convenios de cooperación a que se refiere el artículo anterior.»

El Real Decreto 1980/1981, de 19 de junio, sobre Constitución de la Comisión Asesora de Libertad Religiosa en el Ministerio de Justicia dicta las normas de desarrollo del artículo 8 de la Ley Orgánica y, en concreto, la composición, competencia y funcionamiento de la misma. Un precedente de esta Comisión podría encontrarse en la Comisión de Libertad Religiosa creada por la Ley de Libertad Religiosa de $44 / 1967^{37}$. No obstante, se trata de dos Comisiones notablemente diferentes, tanto por su composición como por su competencia. La precedente Comisión estaba integrada exclusivamente por representantes de la Administración ${ }^{38}$, mientras que, en la actual, la representación de la Administración se reduce a la tercera parte de sus miembros; los otros miembros son representantes de las confesiones y expertos.

Más importantes, sin embargo, son las diferencias en relación con la competencia. La anterior Comisión tenía como función el «estudio, informe y propuesta de reducción de todas las cuestiones administrativas relacionadas

${ }^{37}$ «La competencia administrativa de todas las cuestiones relacionadas con el derecho civil a la libertad religiosa corresponde al Ministerio de Justicia. Como brgano del mismo se constituirá en la Subsecretaría una Comisión de Libertad Religiosa» (art. 34.1).

${ }_{38}$ «La citada Comisión estará integrada por el subsecretario del Ministerio de Justicia como presidente; un representante de cada uno de los Ministerios de Asuntos Exteriores, Gobernación, Educación y Ciencia e Información y Turismo, designados por sus titulares; un representante del Alto Estado Mayor, un representante del Consejo Nacional del Movimiento, un representante de la Organización Sindical, el director general de Asuntos Eclesiásticos, el director general de lo Contencioso del Estado en representación del ministro de Hacienda, un funcionario del Ministerio Fiscal y otro del Cuerpo Especial Técnico de Letrados del Ministerio de Justicia con categoría de magistrado, designados por el titular del Departamento» (art. 34.2). 
'con el ejercicio del derecho civil a la libertad religiosa». La competencia de la actual Comisión es más amplia: a) Por una parte, corresponden a la Comisión «las funciones de estudio, informe y propuesta de todas las cuestiones relativas a la aplicación de la Ley Orgánica de Libertad Religiosa». Se produce aquí un cambio importante, puesto que la Ley de Libertad Religiosa de 1967 era de aplicación tan sólo para las Asociaciones religiosas no católicas, con exclusión total de la Iglesia católica. La Ley Orgánica vigente es de aplicación para todas las confesiones religiosas, incluida la Iglesia católica. Existe, por tanto, un cambio sustancial en el cometido de la Comisión, ya que quedan comprendidas entre sus funciones el asesoramiento en la aplicación de la ley, en lo que afecta a la Iglesia católica, sin perjuicio de la competencia de la Comisión mixta Iglesia-Estado, tema que abordaremos más adelante. $b$ ) Por otra parte, corresponde también; particularmente y con carácter preceptivo, «la preparación y dictamen de los acuerdos o convenios de cooperación a que se refiere el artículo séptimo de la LOLR». La inclusión de esta función establece ya una diferencia radical con la anterior Comisión.

Al margen de las diferencias apuntadas existe un hecho diferencial más profundo, que excluye cualquier concomitancia entre ambas Comisiones. El cambio profundo en la consideración del factor religioso que instaura la Constitución y desarrolla la Ley.Orgánica, pasando de un régimen de confesionalidad con libertad religiosa a un régimen de libertad religiosa sin confesionalidad, obligan a rechazar plenamente cualquier similitud entre ambos organismos.

\section{La composición de la Comisión Asesora}

La Comisión Asesora, como ya hemos dicho, está integrada por representantes de la Administración, de las confesiones y expertos. La LOLR establece que esta composición tendrá forma paritaria y carácter estable. Una primera lectura podría sugerir que se trata de una Comisión mixta Estadoconfesiones. Una más atenta lectura desecha esta posible interpretación. Una Comisión mixta Estado-confesiones sería bipartita, no tripartita; los expertos serían aportados por cada parte en su calidad de técnicos $y$, por tanto, sin el carácter de miembros que fija la ley.

El carácter tripartito elimina la posibilidad de calificar la Comisión como mixta. Apoya este argumento la dificultad o imposibilidad de que exista una representación gènuina de las confesiones. Habida cuenta de la dispersión de confesiones inscritas en el Registro público del-Ministerio de Justicia, resulta difícil pensar que pudiera llegarse a una representación auténtica de las mismàs que no fuera asamblearia. Se comprende así que el Real Decreto que regula la Comisión diga al respecto que los representantes de las confesiones serán designados por el ministro de Justicia después de oídas las confesiones que se hallan inscritas en el Registro de Entidades Religiosas.

Examinada la composición de la Comisión Asesora, parece más lógico pensar que, en lugar de ser una Comisión mixta, se trata de un organismo estatal integrado por representantes de la Administración y por miembros que, por su calificación personal - vinculación a una confesión o competencia técnica-, 
resulten más idóneos a juicio del Gobierno para prestar su asesoramiento en orden a la mejor aplicación de la LOLR.

En efecto, el artículo 1 del Real Decreto $1980 / 81$, de 19 de junio, sobre constitución de la Comisión Asesora de Libertad Religiosa en el Ministerio de Justicia determina que dicha Comisión estará integrada:

a) Por el director general de Asuntos Religiosos como presidente.

b) Un representante de cada uno de los Ministerios de la Presidencia del Gobierno, Hacienda, Interior, Educación y Ciencia y Cultura, designados por sus titulares.

c) Siete representantes de las Iglesias, confesiones y comunidades religiosas o federaciones de las mismas, entre las que, en todo caso, estarán las que tengan arraigo notorio en España, designadas por el ministro de Justicia después de oídas las confesiones que se hallan inscritas en el Registro de Entidades Religiosas.

d) Siete personas de reconocida competencia, designadas por acuerdo del Consejo de Ministros a propuesta del ministro de Justicia. secretario.

e) El letrado jefe del Servicio de Asuntos Religiosos, que actuará como

La Comisión Asesora es, por tanto, un organismo del Ministerio de Justicia, presidido por el director general de Asuntos Religiosos, y sus miembros, nombrados por el Consejo de Ministros (expertos), por los ministros del ramo (representantes de los Ministerios) y por el ministro de Justicia (representantes de las confesiones). No se trata, por consiguiente, de una Comisión mixta Estado-confesiones con representantes elegidos y nombrados libremente por cada una de las partes, sino de una Comisión estatal cuyos miembros son nombrados por órganos del Estado con la finalidad de asesorar en la aplicación de la legislación común del Estado en materia religiosa.

La presencia de miembros de las confesiones religiosas en la Comisión debe entenderse en función del interés general y no de un interés particular, como representantes de la confesión ante el Estado; muy al contrario, su presencia se justifica como miembros de un organismo del Estado para asesorar en la aplicación correcta del derecho común eclesiástico a que hemos hecho mención en páginas anteriores.

La previsible exclusión de la competencia de la Comisión Asesora del derecho específico de cada confesión, surgido en virtud de un acuerdo o convenio con el Estado, no justifica en absoluto la ausencia de representantes de dicha confesión en la Comisión Asesora. Se trata de dos marcos jurídicos distintos - aunque complementarios- y dos posiciones diversas. Por una parte, la interpretación del derecho específico acordado con una confesión. Por otra, la presencia, a todos los efectos y con todas las consecuencias, en un organismo estatal (Comisión Asesora de Libertad Religiosa); presencia muy distinta de la que correspondería al miembro de una confesión en una Comisión de interpretación de un acuerdo, que no tendría el carácter de organismo estatal, sino de Comisión mixta Estado-confesión.

En conclusión, partiendo del interés común a todas las confesiones de que se aplique y desarrolle con plenas garantías y eficacia el principio de libertad religiosa establecido en nuestra Constitución, parece obvio que la pre- 
sencia de una confesión en la Comisión Asesora de Libertad Religiosa no es incompatible con su presencia en una Comisión mixta; más bien supone una explícita manifestación de espíritu cívico y de colaboración con el Estado en la consecución del interés general y en la aplicación del principio de libertad religiosa sancionado en nuestra Constitución.

\section{Competencia de la Comisión Asesora}

La función de la Comisión es específicamente consultiva: se trata de un organismo asesor del ministro de Justicia en orden a la aplicación de la LOLR. Su intervención, sin embargo, tan sólo es preceptiva en la preparación y dictamen de los acuerdos o convenios de cooperación del Estado con las confesiones. Según lo dispuesto en la Ley Orgánica, esta última es la función peculiar y preferente de la Comisión Asesora. En las restantes cuestiones relativas a la aplicación de la ley no se requiere preceptivamente su informe; en cambio, no podrá suscribirse ningún acuerdo o convenio si previamente no ha sido constituida dicha Comisión, ya que, además de evacuar el correspondiente dictamen, la Comisión debe intervenir preceptivamente en la preparación del acuerdo o convenio.

La importancia de esta función de la Comisión reside en el significado propio de los acuerdos como fuentes del Derecho eclesiástico. A la larga tradición del Concordato como fórmula jurídica de concreción de las relaciones de la Iglesia con el Estado hay que añadir la tendencia del Derecho contemporáneo a la utilización de la normativa pactada por el Estado, dando participación a los grupos sociales en la génesis de las normas que les afectan; se trata de una evolución, ciertamente interesante, del derecho impuesto al derecho pactado. Evolución que refleja el cambio paulatino en la concepción del Estado y del poder y una reconsideración del papel de la sociedad en la creación del Derecho, evolución que afecta igualmente a la propia concepción del Derecho.

La Constitución de 1978 ha mostrado una gran sensibilidad en este tema y abre cauces generosos para la participación de los grupos sociales en la elaboración de las normas relativas a su propio status jurídico. La LOLR ha interpretado con fidelidad este espíritu de la Constitución al concretar las relaciones de cooperación de que hace mención el artículo 6.3 en la fórmula jurídica de acuerdos o convenios. Se abre así al Derecho eclesiástico español esta fuente normativa, coherente con el espíritu de la Constitución, ampliando los cauces tradicionales de entendimiento del Estado con la Iglesia católica, por vía concordataria, a otra confesiones religiosas. El Derecho eclesiástico español asume así experiencias significativas del Derecho comparado moderno, tales como los Kirchenverträge del Derecho alemán o las intese previstas en el artículo 3 de la Constitución italiana ${ }^{39}$.

${ }^{39}$ Véanse A. M. Rouco Varela, «Los tratados de las Iglesias protestantes con los Estados», en La institución concordataria en la actualidad, Salamanca, 1971, págs. 105-133; G. Casuscelli, Concordate, intese e pluralismo confessionale, Milán, 1974; Varios, Le intese tra Stato e Confessione religiose: problemi e prospettive, Milán, 1978. 
El artículo séptimo de la LOLR regula esta cuestión en los siguientes términos: «Uno. El Estado, teniendo en cuenta las creencias religiosas existentes en la sociedad española, establecerá, en su caso, acuerdos o convenios de cooperación con las Iglesias, confesiones y comunidades religiosas inscritas en el Registro que por su ámbito y número de creyentes hayan alcanzado notorio arraigo en España. En todo caso, estos acuerdos se aprobarán por ley de las Cortes Generales. Dos. En los acuerdos o convenios, y respetando siempre el principio de igualdad, se podrá extender a dichas Iglesias, confesiones y comunidades los beneficios fiscales previstos en el ordenamiento jurídico general para las entidades sin fin de lucro y demás de carácter benéfico.» Sin entrar en el análisis completo de este texto, vamos a considerar algunos aspectos que interesan al presente estudio.

a) Todos los acuerdos suscritos entre el Estado y las confesiones religiosas deberán ajustarse a lo dispuesto en el artículo séptimo de la LOLR. Dado que la Ley Orgánica es posterior a la firma de los acuerdos de la Santa Sede, es obvio que tales acuerdos no se han realizado según lo dispuesto en dicho artículo. Esto plantea un problema de homogeneización jurídica de los acuerdos en dos aspectos concretos: $a^{\prime}$ ) la naturaleza jurídica de los acuerdos con la Iglesia católica - tratados internacionales-y de los acuerdos con otras confesiones; $b^{\prime}$ ) la armonización del derecho común contenido en la Ley Orgánica y el derecho específico surgido de los acuerdos.

La Iglesia católica goza de personalidad en el orden internacional. Los Estados reconocen esta personalidad, y los convenios que suscriben con la Iglesia católica adoptan la forma de tratados internacionales. No nos vamos a extender en este tema por ser sumamente conocido y aceptado pacíficamente en sede doctrinal ${ }^{40}$. Esta praxis diplomática ha sido adoptada por el Gobierno español para suscribir los acuerdos con la Santa Sede de 3 de enero de 1979. Se ha seguido, en efecto, el procedimiento previsto para los tratados internacionales en el artículo 94 de la Constitución, $\mathrm{y}$, de acuerdo con este procedimiento, las Cortes Generales autorizan la ratificación de los acuerdos con la Santa Sede.

Este hecho constituye el primer punto de colisión con la LOLR, que, en su artículo 7, prevé que en todo caso los acuerdos se aprobarán por ley de las Cortes Generales. Ciertamente, los acuerdos no han seguido para su aprobación los trámites de una ley ordinaria, sino los de un tratado internacional, y de ahí se deriva que ambas partes quedan vinculadas en un ámbito jurídico superior al de sus respectivos ordenamientos. Mientras la LOLR prevé la celebración de acuerdos con las confesiones religiosas aprobados mediante ley de las Cortes Generales y, por consiguiente, como normas de derecho interno, los acuerdos con la Santa Sede se caracterizan por ser tratados internacionales y normas de derecho público externo.

¿Estamos en presencia de una quiebra del principio de igualdad jurídica o de una distinta regulación en razón de la distinta especificidad de cada confesión? Es claro que la Iglesia católica es la única confesión que goza de personalidad internacional y, por consiguiente, en razón de su propia especificidad

${ }^{40}$ Véase J. Calvo, Concordato y acuerdos parciales: Politica y Derecbo, Pamplona, 1977. 
es coherente el procedimiento seguido por el Estado español para la conclusión de los acuerdos con la Santa Sede: la vía de los tratados internacionales.

Queda la duda, sin embargo, acerca del procedimiento a seguir con las demás confesiones. ¿Por: motivos de equiparación con la Iglesia católica se tenderá a equiparar la ratificación de los acuerdos con las demás confesiones a las normas de derecho público externo? Se plantea aquí una cuestión de difícil solución: la armonía de los acuerdos suscritos con la Santa Sede -y los que puedan suscribirse en el futuro- con la Ley Orgánica de Libertad Religiosa. Ciertamente, el procedimiento seguido para la ratificación de los acuerdos ha sido correcto y su homologación con los tratados internacionales es una práctica común en el Derecho internacional. En lo sucesivo, si se procede a suscribir nuevos acuerdos, a modificar o sustituir los existentes, será obligado seguir el mismo procedimiento.

Esta situación, sin embargo, supone una clara discrepancia con lo dispuesto en la Ley Orgánica de Libertad Religiosa, que no contempla la posibilidad del acogimiento al procedimiento de los tratados internacionales, sino la aprobación de los acuerdos con las confesiones religiosas como ley ordinaria. En nuestra opinión, la cuestión no se plantea en los términos de una posible desigualdad de tratamiento de la Iglesia católica y de las demás confesiones. Teniendo en cuenta que la igualdad jurídica no significa uniformidad jurídica y que el Estado debe regular el factor religioso en función de la propia especificidad de cada confesión, resulta correcto suscribir acuerdos con la Iglesia católica con rango de tratado internacional -atendida su propia peculiaridad como confesión con personalidad en el Derecho internacional一; en cambio, la aprobación de los acuerdos con otras confesiones deberá hacerse por medio de ley ordinaria, habida cuenta que éstas carecen de ese reconocimiento internacional.

El problema, por tanto, hay que situarlo en el carácter restrictivo de la LOLR al disponer un régimen uniforme para todas las confesiones, olvidando la personalidad internacional de la Iglesia. Habría sido más acertado sustituir la fórmula de la ley: «Estos acuerdos se aprobarán por ley de las Cortes Generales», por otra más amplia: «Estos acuerdos serán ratificados o aprobados por las Cortes Generales».

No cabe la menor duda de que la redacción actual excluye la posibilidad de celebrar nuevos convenios con la Santa Sede, pues o ésta renuncia a su personalidad internacional en este supuesto - cosa harto improbable - o se formalizan en un acto expreso contra legem, con la quiebra del orden jurídico que esto entraña. En sede doctrinal, la cuestión parece insoluble si no se procede a la rectificación del texto legal.

Esta misma situación plantea la viabilidad del procedimiento establecido en el complejo normativo vigente para la elaboración de los acuerdos con las confesiones y en concreto en el supuesto de elaboración ex novo o de revisión de los existentes con la Iglesia católica. El Derecho común establece para todas las confesiones que la Comisión Asesora de Libertad Religiosa participará, con carácter preceptivo, en la preparación y dictamen de todos los acuerdos. Ahora bien: si en base a la excepcionalidad de la Iglesia católica -como consecuencia de su personalidad internacional - no es de aplicación el artículo 7 de 
la LOLR, ¿̇e podría invocar, a los efectos de preparación y dictamen de dichos acuerdos, el artículo 8 de dicha Ley? La redacción del artículo 7 puede dar lugar a una delicada situación que podría pretextar la exclusión de la Iglesia católica del régimen común de la LOLR, dando lugar, en este caso sí, a una desigualdad jurídica contraria a lo dispuesto en la Constitución.

Otra cuestión que merece ser comentada, como consecuencia de la firma de los acuerdos con la Santa Sede de 3 de enero de 1979, es el contenido de los mismos y su interpretación y aplicación. En estos acuerdos se regulan asuntos jurídicos, enseñanza, asuntos culturales, asistencia religiosa a las fuerzas armadas, servicio militar de clérigos y religiosos y asuntos económicos. Se trata de un conjunto de materias amplio que abarca desde el status jurídico de la Iglesia en España hasta el régimen de su actividad en distintas funciones de carácter social.

La aplicación e interpretación de estas normas se hará de común acuerdo entre las altas partes contratantes: «La Santa Sede y el Gobierno español procederán de común acuerdo en la resolución de las dudas o dificultades que pudieran surgir en la interpretación o aplicación de cualquier cláusula del presente acuerdo, inspirándose para ello en los principios que lo informan» ${ }^{41}$.

Resulta evidente que el derecho específico pactado entre la Iglesia y el Estado queda al margen de la competencia de la Comisión Asesora de Libertad Religiosa. Sin entrar en la valoración de esta exclusión, cabe plantear si, por homologación, se va a seguir este criterio en la firma de los respectivos acuerdos con las otras confesiones, creando comisiones ad boc para cada acuerdo en concreto. Si se sigue este criterio, se acabará delineando un cuerpo normativo común y un cuerpo normativo específico, correspondiendo a la Comisión Asesora tan sólo la función consultiva en aquellas cuestiones relativas a la aplicación del derecho común.

Esta segregación del complejo normativo específico de cada confesión del derecho común eclesiástico puede llevar consigo un debilitamiento de la competencia de la Comisión Asesora y, en última instancia, a la renuncia por parte de las confesiones religiosas que hayan alcanzado su correspondiente acuerdo a estar presentes en la Comisión. Cualquiera que sea la solución a la que se llegue, esta actitud sería gravemente errónea, ya que la Constitución y la LOLR establecen el derecho común eclesiástico del Estado, que es, por su propia naturaleza, primario y prevalente para todos los ciudadanos. Pues bien: la aplicación de este derecho común constituye la competencia propia -en su función asesora - de la Comisión, que, por otra parte y como antes se ha dicho, no es un organismo representativo de las confesiones, sino un organismo del Estado. La presencia de los representantes de las confesiones garantizará una más perfecta aplicación del derecho común eclesiástico, contribuyendo a que el derecho de libertad religiosa se encauce y arraigue con mayor plenitud en la realidad social de nuestro país.

b) La LOLR concreta las características que deberán reunir las con-

${ }^{41} \mathrm{La}$ cláusula se repite en los diferentes acuerdos: Acuerdos sobre Asuntos Jurídicos, art. 7; Acuerdo sobre Enseñanza y Asuntos Culturales, art. 16; Acuerdo sobre la Asistencia a las Fuerzas Armadas y Servicio Militar de Clérigos y Religiosos, art. 7; Acuerdo sobre Asuntos Económicos, art. 6. 
fesiones religiosas para que puedan establecer acuerdos de cooperación con el Estado. Se requiere, en primer lugar, que las confesiones estén inscritas en el Registro de Entidades Religiosas; en segundo lugar, que hayan alcanzado notorio arraigo en función de su ámbito y número de creyentes.

Podría interpretarse que la ley restringe el mandato constitucional que se refiere a todas las confesiones; sin embargo, el establecimiento de los anteriores requisitos resulta coherente con el propio texto constitucional, que determina que «los poderes públicos tendrán en cuenta las creencias religiosas de la sociedad española» $\mathrm{y}$, a continuación, prescribe la obligación de mantener las relaciones de cooperación.

La Constitución atribuye a los poderes públicos la valoración social de las creencias religiosas, es decir, su arraigo y extensión, lo que coincide con los requisitos establecidos en la Ley Orgánica. La prueba del arraigo corresponde a las propias confesiones y a los poderes públicos valorar si es suficiente para establecer los referidos convenios. La Comisión Asesora debe desempeñar en este punto un importante papel, pues, por su variada composición, puede emitir un dictamen ajustado e imparcial sobre la pertinencia de los acuerdos en cada caso.

c) Ya hemos hecho mención de la forma de aprobación de los acuerdos. La LOLR dice expresamente: «se aprobarán por ley de las Cortes Generales». Con anterioridad se ha evidenciado la dificultad de armonizar esta prescripción con la personalidad internacional de la Iglesia católica y en concreto de los acuerdos suscritos con la misma el 3 de enero de 1979. Tratado este tema en otro apartado antetior, vamos a considerar brevemente los acuerdos con otras confesiones.

El procedimiento a seguir, de acuerdo con la Ley, será: la preparación y dictamen preceptivo por parte de la Comisión Asesora de Libertad Religiosa, remisión por el Ministerio de Justicia al Consejo de Ministros, aprobación por el Consejo de Ministros como proyecto de ley, aprobación — siguiendo el iter parlamentario- por el Congreso de Diputados y el Senado como ley ordinaria y, por último, la sanción real.

La doctrina - española y extranjera - se ha planteado la cuestión de la naturaleza jurídica de estos acuerdos ${ }^{42}$. Hollerbach y Albrech entienden «que la regulación de las relaciones Iglesia y Estado.... independientemente de las diferencias eclesiológicas de las distintas confesiones cristianas, obedece a un orden jurídico propio que está por encima del ordenamiento jurídico del Estado, pero que es distinto del Derecho internacional, al que responden como instrumento jurídico de tradición histórica normativa los tratados del Estado con las Iglesias» ${ }^{43}$.

Esta interpretación presenta serias dificultades, pues, al carecer las confesiones religiosas - salvo la católica - de personalidad internacional, resulta difícil concebir que el acuerdo tenga un valor superior al de presupuesto de una ley. Su promulgación daría lugar a una norma de Derecho interno y no de Derecho internacional.

42 Cfr. Lombardía, ob. cit., pág. 198.

${ }^{43}$ Cit. por A. M. Rouco Varela, «Los tratados...», cit., pág. 130. 
Una posición intermedia ha sido seguida por un sector de la doctrina italiana. Finocchiaro, aproximando los acuerdos a la figura del Concordato, los considera «actos vinculantes para el Estado en un ordenamiento que surge en el momento mismo en que el Estado y las confesiones acatólicas estipulan el acuerdo». Estas normas, aun no siendo de rango internacional, tampoco son Derecho interno del Estado ${ }^{44}$. El acuerdo comportaría una obligación de Derecho externo, que no podría ser derogado unilateralmente por el Estado.

Esta posición, que no es seguida por la mayoría de la doctrina italiana, ha sido descartada por Rouco Varela, que, tras haber estudiado el tema en el Derecho eclesiástico alemán, ha concluido que «entre Derecho estatal y Derecho internacional non datur tertium genus» ${ }^{45}$.

Entre nosotros, y siguiendo la doctrina jurídica sobre la naturaleza de la ley paccionada en .el Derecho navarro - supuesto que podría extenderse a los Estatutos de Autonomía hoy vigentes-, Lombardía sostiene la posibilidad en España de este tercer ordenamiento distinto del internacional y del estatal y aplicable al ordenamiento estatal.

«Concebidas como paccionadas - dice Lombardía - las leyes que se dicten en aplicación del número 1 del artículo 7 de la LOLR, el ordenamiento jurídico español habrá aportado cuanto de él depende a la igualdad formal entre las confesiones en el establecimiento de normas basadas en la cooperación. En todos los casos, el Estado pacta con los interlocutores válidos de las confesiones, y la eficacia del pacto opera en las vicisitudes ulteriores de la vigencia de la ley estatal.

Obviamente, el fundamento de la eficacia de un tratado internacional autorizado a tenor del artículo 94 de la Constitución y el de una ley paccionada no son idénticos, pero tienen grandes analogías a efectos prácticos. Las diferencias dependen del distinto modo de entender su propia identidad como grupos religiosos la Iglesia católica y las demás confesiones y de la personalidad internacional de la Santa Sede, datos estos que no crea el Estado, sino que se le presentan como presupuesto» ${ }^{46}$.

\section{Funcionamiento}

El Real Decreto 1980/81 dispone que la Comisión funcionará en Pleno y en Permanente. Al Pleno le corresponden las funciones expuestas en el apartado anterior. Estará presidido por el director general de Asuntos Eclesiásticos y se reunirá preceptivamente una vez al año. Cuando la naturaleza de los asuntos lo requiera, el presidente podrá convocar la Comisión en Pleno para tratar de los mismos. También procede la convocatoria de la Comisión si lo solicita la mayoría de los vocales. El ministro de Justicia podrá presidir la Comisión —en Pleno o en Permanente- siempre que lo estime oportuno.

La Comisión Permanente tendrá la competencia que le delegue el Pleno. Está presidida por el director general de Asuntos Eclesiásticos; el secretario

4 P. Lombardía, ob. cit., pág. 199.

${ }^{45}$ Rouco Varela, ob. cit., pág. 133.

${ }^{4}$ Ob. cit., págs. 200-201. 
es el del Pleno, es decir, el letrado jefe del Servicio de Asuntos Religiosos. Estará integrada además por cuatro vocales elegidos por el Pleno de entre sus miembros, dos de ellos representantes de las Iglesias y otros dos representantes de los expertos. A las reuniones de la Comisión Permanente podrán ser llamados el vocal o vocales del Pleno, siempre que la cuestión a tratar afecte a su departamento o Iglesia.

Además de la competencia delegada del Pleno, la Permanente conocerá de aquellos asuntos que por su carácter urgente le encomiende el ministro de Justicia, realizando los oportunos estudios y evacuando los pertinentes informes y propuestas. De estos actos se dará cuenta al Pleno en la primera sesión que celebre.

La Secretaría de la Comisión, cuya titularidad, como he dicho, corresponde al letrado jefe del Servicio de Asuntos Religiosos, tiene encomendadas las siguientes funciones: a) estudio, información y asesoramiento de carácter técnico; b) coordinación; c) supervisión de los servicios que dependen de la Dirección General de Asuntos Religiosos. 